At Skokholm Bird Observatory, 6,635 birds were ringed during the year, most of them shearwaters and gulls, but including members of 50 other species. As from the beginning of 1963, Dr. D. Lack, of the Edward Grey Institute, shares with the Council the scientific control of the Observatory for an experimental period. The report contains an article by J. M. F. Cannon, of the British Museum (Natural History), suggesting ways in which museums and field centres might co-operate in teaching basic ecology. More than half the students at these centres come from sixth forms at grammar schools, and about equal numbers from universities and teacher training colleges, together making up a quarter. The remainder are amateurs with a variety of interests. Of the subjects studied, rather more than half are biological, and a third are concerned with geography and geology, but the centres also have something to offer to artists and archæologists, and on a reduced scale they provide a selection of other courses. With due allowance for grants for capital and income, the Council's finances are in a healthy condition.

\section{Soil Research in Australia}

AFTER 33 years, the headquarters of the Commonwealth Scientific and Industrial Research Division of Soils has been established at Adelaide, but various centres and subcentres throughout Australia are established to deal with regional problems. The annual report for the year ending June 30,1962 , demonstrates forcibly the great variety of investigations that are at present being pursued in the interests, both short- and long-term, of agriculture in Australia (Pp. $v+97$. Adelaide: Commonwealth Scientific and Industrial Research Organization, 1962). Progress has seen new developments in laboratory techniques with increasing emphasis on the links between mineralogy, geochemistry and field pedology and on the importance of soil physics as an environmental factor in plant growth. The new soil map of Australia has been contributed to the Food and Agriculture Organization-Unesco World Soil Map Project, and a third edition of the Manual of Australian Soils has been issued. There are reports of investigations on the nutrition of Pinus radiata, the residual value of superphosphate, water-repellent sands, trace elements, the distribution of saline soils, the effect of tillage tools on soil structure and of soil structure on permeability. There are short accounts of numerous studies on such topics as Rhizobium variants, the bioassay of soil toxicity, the decomposition in the soil of aromatic nitrogenous compounds, layer lattice silicates, the effect of freezing on the swelling of clay minerals, and fabric analysis. These are but a selection to illustrate the nature and extent of the work being carried out. A list of staff and references to recent publications complete a most useful survey of soil science in Australia.

\section{The Queen Victoria Museum, Launceston, Tasmania}

THE Records of the Queen Victoria Museum, Launceston, New Series No. 15, consists of one paper only-a list of Tasmanian Aboriginal material in collections in Europe by Mr. N. J. B. Plomley, of University College, London (Pp. 8. Launceston, Tasmania: Queen Victoria Museum and Art Gallery, 1962). The paper is mainly compilative and does not attempt to be analytical. It will, however, form a very valuable survey for those who require details of Tasmanian Aboriginal material in the museums of Europe. The annual report of this Museum for 1960-61 records that two major building projects were completed during the year (Pp. 18. Launceston, Tasmania: Queen Victoria Museum and Art Gallery, 1962). During the period a new Physical Science Wing was opened and as an appropriate special feature an exhibition entitled "Australia and the Atom" was presented by the Australian Atomic Energy Commission. This exhibition was followed by one on engineering, trades and skilled crafts arranged as a contribution towards the Duke of Edinburgh's Technical Training Week.

\section{History of Science in India}

The Indian Council of Scientific and Industrial Research has established a History of Science Unit to carry out primarily studies on the historical development of science in India. The Unit is charged with compiling a comprehensive bibliography of scientific manuscripts available in various Indian languages in different periods of Indian history, and prepares subject and period histories of different branches of science, and a comprehensive history of the development of seience and technology in India. It will also work on the social implications of science and the impact of science on modern Indian society. Further information can be obtained from A. Rahman, History of Science Unit, Council of Scientific and Industrial Research, New Delhi.

\section{Nuclear Engineering Abstracts}

THE fourth issue of Nuclear Engineering Abstracts reports on relevant literature published during 1960, and completes the initial trial period in which the periodical has endeavoured to establish its own policy and its place in the technical publishing world $(2$, No. 2 . London: Silver End Documentary Publications, Ltd., 1962. Annual subseriptions covering 3 issues, post paid $£ 66 s$. or 18.50 dollars). It has, however, fallen behind with publication, and rising costs will severely limit future development. It has been decided, therefore, that the present issue completes Volume 2 and also terminates the quarterly subscription to the Abstracts. All subsequent issues will be at four-monthly intervals, with threo issues comprising one volume to coincide with the calendar year and to be available at the same subseription price as before. The January issue 1963 is Volume 4, No. 1, and will cover papers published during January-April 1962. Volume 3, the link issue covering papers published during 1961, will be made available on a special subscription basis at a later date and subscriptions will be invited when preparation of Volume 3 has reached a point where delivery can be promised. Volume 1, No. 1 , is out of stock, but a reprint is under consideration.

\section{A New X-Ray Spectrometer}

THE SPG-3 X-ray spectrometer for spectrochemical analysis in controlled atmospheres, recently introduced by the General Electric Co. of America, is more versatile than the SPG-4, which it now replaces. Elements of magnesium and higher atomic number in vacuo, air, helium or other desired atmospheres can be analysed without modification. The spectrometer has a unique hand elutch which can disengage the worm gear of the drive mechanism to shift analytical positions in a few seconds. Independent or simultaneous photon measurement can be made by two counter tubes located within the vacuum chamber. Selection is made by remote control from outside the chamber. Samples are loaded through a 4-in. port, equipped with a positive interlock system that prevents the possibility of radiation exposure. The samples may be either foil or up to $1_{4}^{1}$ in. thick, and can be $2 \frac{1}{2}$ in. $\times 2 \frac{1}{2}$ in. square or 3 in. in diameter. The vacuum pump and heat exchanger are mounted within the spectrometer table, and entry for the counter-tube gas and appropriate atmospheres is located on a rear bulkhead of the vacuum chamber.

\section{Stone Age Tools from Mysore State}

M. Seshadri, in a recent publication from Mysore University, reports a collection of artefacts from Salvadgi (Stone Age Tools from Salvadgi, Bijapur District, Mysore State. The half-yearly Journal of the Mysore University. Section A. Arts, 21 , No. 2; 1962). The author states that the site could be excavated, although the present assemblage has been collected without excavation and is pre- 